\title{
PPM1D dephosphorylates Chk1 and p53 and abrogates cell cycle checkpoints
}

\author{
Xiongbin Lu, ${ }^{1}$ Bonnie Nannenga, ${ }^{2}$ and Lawrence A. Donehower ${ }^{1,2,3}$ \\ ${ }^{1}$ Department of Molecular Virology and Microbiology and ${ }^{2}$ Department of Molecular and Cellular Biology, \\ Baylor College of Medicine, Houston, Texas 77030, USA
}

\begin{abstract}
The ATM (ataxia-telangiectasia mutated) and ATR (ataxia-telangiectasia and Rad3-related) kinases respond to DNA damage by phosphorylating cellular target proteins that activate DNA repair pathways and cell cycle checkpoints in order to maintain genomic integrity. Here we show that the oncogenic p53-induced serine/threonine phosphatase, PPM1D (or Wip1), dephosphorylates two ATM/ATR targets, Chk1 and p53. PPM1D binds Chk1 and dephosphorylates the ATR-targeted phospho-Ser 345, leading to decreased Chk1 kinase activity. PPM1D also dephosphorylates p53 at phospho-Ser 15. PPM1D dephosphorylations are correlated with reduced cellular intra-S and G2/M checkpoint activity in response to DNA damage induced by ultraviolet and ionizing radiation. Thus, a primary function of PPM1D may be to reverse the p53 and Chk1-induced DNA damage and cell cycle checkpoint responses and return the cell to a homeostatic state following completion of DNA repair. These homeostatic functions may be partially responsible for the oncogenic effects of PPM1D when it is amplified and overexpressed in human tumors.
\end{abstract}

[Keywords: p53; PPM1D; Wip1; ATM; ATR; Chk1]

Received December 20, 2004; revised version accepted April 4, 2005.

The p53 tumor suppressor is a critical stress response protein that mediates diverse antiproliferative functions in the cell in part through its role as a transcription factor (Vousden and Lu 2002). Among the many transcriptional targets of p53 is the serine/threonine phosphatase, PPM1D (or Wip1). PPM1D was originally isolated by Appella and colleagues in a screen for ionizing radiation (IR)-induced transcripts in WMN Burkitt lymphoma cells (Fiscella et al. 1997). PPM1D is induced by ultraviolet (UV), IR, methyl methane sulfonate, anisomysin, and $\mathrm{H}_{2} \mathrm{O}_{2}$ in a p53-dependent manner (Fiscella et al. 1997; Takekawa et al. 2000). There are four main classes of serine/threonine phosphatases, Type 1 (e.g., PP1), Type 2A (PP2A), Type 2B (PP2B), and Type 2C (PP2C $\alpha)$ (Mumby and Walter 1993). The PPM1D sequence shows significant region-specific homology with type $2 \mathrm{C}$ protein phosphatases (PP2Cs) (Fiscella et al. 1997; Choi et al. 2000). In vitro studies confirmed that the PPM1D protein has $\mathrm{Mg}^{2+}$-dependent serine/threonine protein phosphatase activity and is insensitive to the inhibitor okadaic acid, characteristics of PP2Cs (Fiscella et al. 1997).

In eukaryotes, one of the roles of PP2Cs is to reverse protein kinase cascades that become activated as a result of stresses (Kyriakis and Avruch 1996). Human PP2C $\alpha$ inhibits the stress responsive p38 mitogen-activated pro-

${ }^{3}$ Corresponding author.

E-MAIL larryd@bcm.tmc.edu; FAX (713) 798-3490.

Article published online ahead of print. Article and publication date are at http://www.genesdev.org/cgi/doi/10.1101/gad.1291305. tein (MAP) kinase pathway (Takekawa et al. 1998). The first identified target of PPM1D was also p38 MAP kinase (Takekawa et al. 2000). p38 MAP kinase is activated by a variety of genotoxic stresses, including UV and $\gamma$ radiation, resulting in rapid phosphorylation at Thr 180 and Tyr 182 (Bulavin et al. 2002a). p38 is physically associated with p53 in vivo and directly phosphorylates p53 on Ser 33 and Ser 46 in response to UV radiation (Bulavin et al. 1999). Phosphorylation of p53 by p38 stimulates p53-mediated transcription and apoptosis (Bulavin et al. 1999). PPM1D selectively inhibits p38 activation by dephosphorylating Thr 180. Thus, PPM1D may facilitate the return of cells to their homeostatic state by down-regulating p53 via p38 inactivation.

Recently, we identified a second dephosphorylation target of PPM1D, the base excision repair enzyme, uracil DNA glycosylase (Lu et al. 2004). PPM1D dephosphorylation of Thr 6 of this DNA repair enzyme suppresses its activity, suggesting that another function of PPM1D may be to homeostatically regulate certain DNA repair activities.

The deactivation of p53 by PPM1D via p38 indicates that overexpressed PPM1D could have oncogenic properties in the appropriate context. In fact, PPM1D overexpression has been reported to induce transformation of primary rodent fibroblasts in cooperation with other oncogenes such as HRas, Myc, and Neu (Bulavin et al. 2002b). Overexpressed PPM1D expedited tumor formation in vivo after injection of mouse embryonic fibroblasts (MEFs) expressing E1A + Ras into nude mice (Bulavin et al. 2002b). While overexpressed PPM1D ap- 
pears to be oncogenic, loss of PPM1D confers resistance to transformation. PPM1D-null mice are considerably more resistant to mammary tumor formation induced by Erbb2 or Hras1 than wild-type or heterozygous PPM1D mice (Bulavin et al. 2004; Harrison et al. 2004). PPM1Dnull MEFs are resistant to transformation by several oncogenes (Bulavin et al. 2004). Lack of PPM1D suppressed transformation through activation of p38 MAPK, followed by activation of $\mathrm{p} 53$ and $\mathrm{p} 16^{\mathrm{INK} 4 \mathrm{~A}}$ (CDKN2A).

Consistent with its behavior as an oncogene in transformation assays, PPM1D expression levels are increased in some human tumor types. In $\sim 15 \%$ of human breast cancers the PPM1D gene is amplified and its RNA overexpressed (Bulavin et al. 2002b; Li et al. 2002; Harrison et al. 2004). Interestingly, virtually none of the tumors with PPM1D amplification carried a p53 mutation, though human breast cancers usually exhibit a $30 \%-40 \%$ frequency in p53 mutations. This is consistent with the idea that overexpressed PPM1D contributes to functional inactivation of $\mathrm{p} 53$, rendering its mutation unnecessary. Recent evidence indicates that PPM1D amplification occurs in other human tumors, including ovarian clear cell adenocarcinomas and neuroblastomas (Hirasawa et al. 2003; Saito-Ohara et al. 2003).

Cell cycle checkpoints are signaling responses that monitor the integrity and replication status of the genetic material before cells commit to either replicate their DNA (in S phase) or segregate their chromosomes (in mitosis) (Zhou and Elledge 2000). Key components of the DNA damage checkpoint are ATM (ataxia-telangiectasia mutated), ATR (ataxia-telangiectasia and Rad3-related), and other protein kinases in the PI3K-related protein kinase family including DNA-PKcs, ATX/SMG1, mTOR/FRAP, and TRRAP (Shiloh 2003; Bakkenist and Kastan 2004a; Sancar et al. 2004). DNA damage mobilizes an intricate signaling network by activating the ATM/ATR protein kinases, which, in turn, orchestrate this network by phosphorylating their target proteins in each pathway. ATM/ATR kinases have been shown to directly phosphorylate p53, MDM2, NBS1, Chk2, BRCA1, Chk1, H2AX, SMC1, and Rad17, along with other proteins (Shiloh 2003). The functional effects of ATM/ATR phosphorylation of these substrates include the arrest of cell cycle progression in one or more of the cell cycle phases, the initiation of programmed cell death responses, and the stimulation of DNA repair processes. The ATM kinase signaling pathway is a major activator of several key proteins that respond in particular to DNA double-strand breaks (DSBs) (Shiloh 2003; Bakkenist and Kastan 2004a). ATM induction is highly sensitive to IR, but not UV. ATR kinase activity is initiated primarily by disruption of DNA replication. ATR responds to UV and IR, in addition to stalled replication (Shiloh 2003). Common targets of ATR include Chk1 and BRCA1, which induce S-phase and G2/M cell cycle arrest upon activation (Shiloh 2003; Bakkenist and Kastan 2004a; Sancar et al. 2004). Chk1 is expressed in the S and G2 phases of proliferating cells and is absent or expressed at very low levels in quiescent and differentiated cells (Bartek and Lukas 2003). It is phosphorylated and activated by ATR at Ser 345 and Ser 317 in response to UV radiation (Shiloh 2003). Chk1, in turn, phosphorylates Ser 216 of the phosphatase CDC25C, which prevents its activation at G2 through 14-3-3-mediated translocation to the cytoplasm (Bartek and Lukas 2003). G2 arrest ensues due to the inability of CDC25C to dephosphorylate inhibitory phosphorylation sites on Cdc2 (CDK1), a primary mitotic kinase.

Phosphorylation and activation of cell cycle checkpoint-associated proteins are initiated by ATM/ATR and their related protein kinases (Shiloh 2003; Sancar et al. 2004). One important question remains largely unanswered: How does the cell turn off these DNA damage response pathways and return to a homeostatic state after DNA repair is completed? It is likely that dephosphorylation by phosphatases is a component of the homeostatic response following DNA damage. Recent evidence has shown that PP5 is involved in the regulation of ATM and DNA-PK, and another phosphatase, PP1, may dephosphorylate Chk1 and allow yeast cells to recover from a DNA damage-induced G2 checkpoint (Ali et al. 2004; Bakkenist and Kastan 2004b). Recent data also indicate that PP2A may regulate autophosphorylation of ATM (Goodarzi et al. 2004). In this paper we show that PPM1D may be one of the phosphatases that contribute to the reversal of the cellular DNA damage response through its dephosphorylation of two ATM/ATR targets, Chk1 and p53. Overexpressed PPM1D is accompanied by a reduction in S-phase and G2/M DNA damage checkpoints, while reduction of PPM1D activity is correlated with more robust intra-S-phase and G2/M checkpoints following DNA damage. Thus, PPM1D may play an important homeostatic function in restoring the damaged cell to a normal state after DNA lesions are repaired.

\section{Results}

\section{PPM1D interacts with Chk1}

To gain further insights into PPM1D function, we attempted to identify PPM1D interacting proteins in a coimmunoprecipitation assay. An interacting $53-\mathrm{kDa}$ protein was identified in lysates from U2OS cells transfected with PPM1D-Flag or PPM1D-V5 expression constructs following immunoprecipitation with Flag or V5 antibody. Western blot analysis of these coimmunoprecipitates with various antibodies revealed that the 53$\mathrm{kDa}$ interacting protein was not $\mathrm{p} 53$, but Chk 1 , which is $54 \mathrm{kDa}$ in size (Sanchez et al. 1997). The Chk1-PPM1D interaction was confirmed by immunoprecipitation Western analysis of U2OS cells cotransfected with GSTChk1 and PPM1D-Flag expression constructs. Western blots of lysates immunoprecipitated with antibodies to tagged versions of PPM1D resulted in positive Chk1 bands when probed with GST antibody (Fig. 1A). When Western blots of lysates immunoprecipitated with Chk1 antibodies were probed with antibodies to PPM1D tags, positive PPM1D bands were observed, confirming that the PPM1D-Chk1 interaction takes place in vivo (data not shown). To show that endogenous PPM1D binds to 
Figure 1. PPM1D binds Chk1. (A) Immunoprecipitation Western analysis shows PPM1D-Chk1 interaction. Chk1-GST and PPM1D tagged with V5 or Flag were introduced into HEK cells and lysates immunoprecipitated with anti-Flag or V5 prior to Western blot probing with a GST antibody. (B) Endogenous PPM1D interacts with endogenous Chk1. (Left panel) Immunoprecipitation of lysates from U2OS cells with anti-PPM1D or control antibody followed by Western blot probing with anti-Chk1 antibody shows that endogenous Chk1 is detected on blots containing immunoprecipitated PPM1D, but not following immunoprecipitation with control antibody. (Right panel) A reciprocal experiment utilizing immunoprecipitation with an anti-Chk1 antibody followed by Western blot probing of the immunoprecipitated lysate with an anti-PPM1D antibody confirmed the endogenous Chk1PPM1D interaction. (C) Diagram of mutant forms of PPM1D constructed to determine Chk1-binding domains. Below the wild-type protein at the top is shown two $\mathrm{N}$-terminal deletion mutants, three phosphatase-dead point mutants, and one C-terminal truncation mutant. The conserved phosphatase domain of PPM1D extends from amino acid 65 to 375. (D) Chk1 binds to mutant forms of PPM1D except for one mutant missing part of the phosphatase domain. Recombinant GST-Chk1 was incubated with in vitro translated and ${ }^{35}$ S-labeled wild-type or mutant PPM1D (upper panel) followed by immunoprecipitation with Chk1 antibodies prior to SDS-polyacrylamide gel electrophoresis and autoradiography (lower panel). Only the PPM1D mutant $\Delta \mathrm{N}(1-101)$ missing key elements of the conserved phosphatase domain did not bind Chk1.

endogenous Chk1, we immunoprecipitated lysates from U2OS cells with anti-PPM1D antibody, followed by Western blot probing with a Chk1 antibody. By this assay, we found that Chk1 is coimmunoprecipitated with PPM1D, indicating a true endogenous interaction between the two proteins (Fig. 1B, left panel). Reciprocal immunoprecipitation Western blot analyses in which U2OS lysates were immunoprecipitated with anti-Chk1 antibody and Western blot probed with PPM1D antibodies confirmed the Chk1-PPM1D interaction (Fig. 1B, right panel). Subsequent experiments to determine the domains of PPM1D that bind to Chk1 indicated that the Chk1 interactions occurred within the conserved phosphatase domain of PPM1D (Fig. 1C,D). Loss of the nonconserved $\mathrm{N}$-terminal and $\mathrm{C}$-terminal domains of PPM1D did not result in loss of binding, nor did phosphatase-dead single point mutations in critical catalytic residues of the PPM1D phosphatase. Only when significant portions of the conserved phosphatase domain (amino acids 65-375) were lost in mutant $\Delta$ N1-101 did binding to Chk1 fail to be observed.

\section{PPM1D dephosphorylates Chk1 in vitro}

We next examined whether PPM1D dephosphorylates Chk1. Purified PPM1D was incubated in an in vitro phosphatase assay with two Chk1-derived phosphopep- tides containing Ser 317 or Ser 345 . These two serines are phosphorylated by the ATR kinase after DNA damage (Liu et al. 2000; Zhao and Piwnica-Worms 2001; Shiloh 2003). PPM1D showed high levels of dephosphorylation of phospho-Ser 345, as well as a positive control peptide containing phospho-Thr 180 from p38 MAP kinase previously shown to be a PPM1D target (Fig. 2A; Takekawa et al. 2000). PPM1D dephosphorylation was minimally inhibited by okadaic acid, an attribute of type $2 \mathrm{C}$ phosphatases (Cohen 1989). Negative control phosphopeptides, including a phosphopeptide derived from the repair protein UNG2(31pT) (Lu et al. 2004) and 13 other phosphothreonine and phosphoserine peptides derived from various proteins failed to show PPM1D dephosphorylation (Fig. 1A; data not shown). Phosphatase reactions in the absence of magnesium also resulted in little or no phosphatase activity, as expected for the magnesium-dependent PPM1D. When another major ATR-targeted serine of Chk1, Ser 317, was tested in the in vitro phosphatase reaction, only modest PPM1D activity was detected on this peptide (Fig. 2A). To show the specificity of PPM1D dephosphorylation, we performed a titration experiment by incubating the Chk1 Ser 345 phosphopeptide with five different purified serine/threonine phosphatases. Increasing amounts of purified PPM1D resulted in increasing levels of free phosphate liberated from the Chk1 Ser 345 phosphopeptide (Fig. 2B). PP1 also 
A

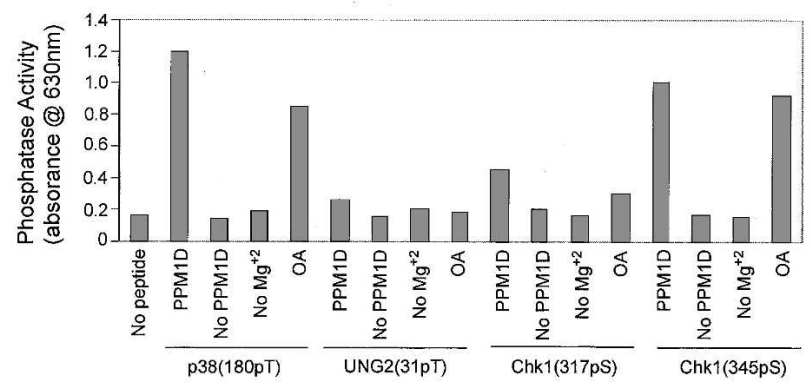

B

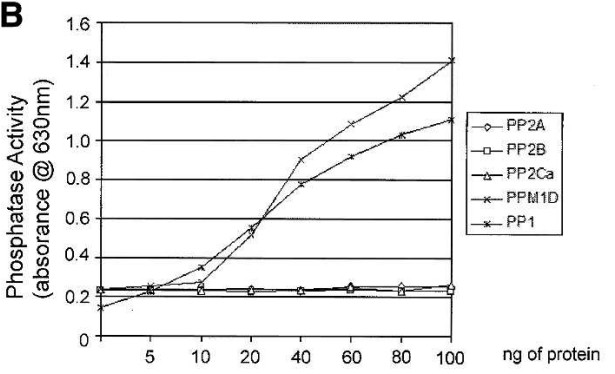

C

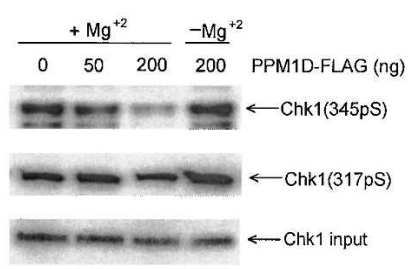

D

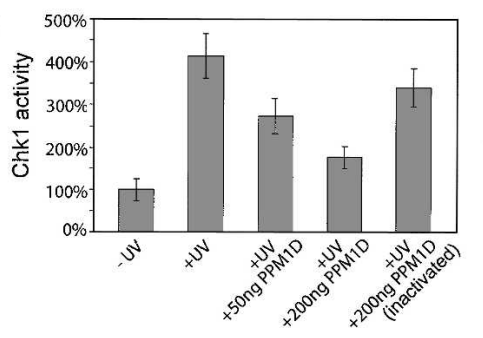

Figure 2. PPM1D dephosphorylates Chk1 phospho-Ser 345 and inhibits Chk1 kinase activity in vitro. (A) PPM1D dephosphorylates Chk1 phospho-Ser 345. Phosphopeptides from p38 MAP kinase (positive control), UNG2 (negative control), and Chk1 (phospho-Ser 317 or phospho-Ser 345) were incubated with PPM1D in an in vitro phosphatase assay. Release of free phosphate was determined by absorbance at $630 \mathrm{~nm}$ in the presence of molybdate dye. Reactions were also performed in the absence of magnesium or peptide or in the presence of okadaic acid. (B) PPM1D and PP1, but not other serine/threonine phosphatases, exhibit in vitro phosphatase activity on a Chk1 phosphopeptide. Indicated amounts of purified serine/threonine phosphatases PPM1D, PP1, PP2A, PP2B, and PP2C $\alpha$ were incubated with Chk1 Ser 345 phosphopeptide in an in vitro phosphatase assay under conditions similar to those in panel $A$. (C) PPM1D dephosphorylates intact Chk1 at phosphoSer 345. An in vitro phosphatase assay was performed by incubating immunoprecipitated Chk1 and purified PPM1D prior to Western blot probing with antibodies to Chk1 phospho-Ser 345 and phospho-Ser 317. (D) PPM1D inhibits Chk1 kinase activity in vitro. Chk1 immunopurified from untreated or UV-treated U2OS cells was incubated with active or inactive PPM1D prior to incubation with a Chk1 target peptide (Ser 216 from CDC25C). (Left panel) Chk1 kinase activity was measured by ${ }^{32} \mathrm{P}$ labeling of substrate peptide. (Right panel) The dephosphorylation of the CDC25C target peptide was not a result of direct PPM1D dephosphorylation because when increasing amounts of purified PPM1D were incubated only with immunopurified CDC25C in the absence of Chk1, no decrease in CDC25C Ser 216 phosphorylation was noted when the Western blot was probed with a CDC25C Ser 216 phosphospecific antibody.

showed high levels of phosphatase activity on this phosphopeptide, consistent with earlier reports that it could target Chk1 Ser 345 for dephosphorylation (Den Elzen et al. 2004; Den Elzen and O'Connell 2004). However, purified PP2A, PP2B, and PP2C $\alpha$ failed to exhibit any activity.

To show that PPM1D dephosphorylates the intact Chk1 protein in vitro, we performed a second set of in vitro phosphatase reactions on immunopurified Chk1 and found that increasing PPM1D resulted in increased Ser 345 dephosphorylation (Fig. 2C). In the absence of magnesium, the magnesium-dependent PPM1D failed to dephosphorylate Chk1. Moreover, Ser 317 on Chk1 was only marginally dephosphorylated by PPM1D in the presence of magnesium, consistent with the results of the in vitro phosphopeptide assays.

\section{Dephosphorylation of Chk1 by PPM1D inhibits Chk1 kinase activity}

To determine whether PPM1D dephosphorylation of Chk1 affects Chk1 kinase activity, we performed an in vitro kinase assay in which a Chk1 target peptide con- taining Ser 216 from CDC25C was incubated with immunopurified Chk1 after preincubation with PPM1D. As expected, Chk1 kinase activity was increased when Chk1 was isolated from UV-irradiated cells compared with unirradiated cells (Fig. 2D). Preincubation with increasing PPM1D reduced Chk1 kinase activity, indicating that PPM1D inhibits Chk1 kinase function. The reduction in phosphorylation of the CDC25C target phosphopeptide was not a result of direct dephosphorylation by PPM1D, as PPM1D incubated with immunopurified CDC25C in the absence of Chk1 exhibited no phosphatase activity on phospho-Ser 216 (Fig. 2D, right panel).

It has been shown that UV treatment induces high levels of PPM1D RNA accumulation in a p53-dependent manner by $8-12 \mathrm{~h}$ post-UV treatment (Takekawa et al. 2000) and we show here that PPM1D protein levels increase by $2-4 \mathrm{~h}$ and peak at $\sim 8 \mathrm{~h}$ in UV-treated U2OS cells (Fig. 3A). Following UV irradiation, there also appear to be gel mobility shifts in the PPM1D protein, suggesting damage-induced post-translational modifications. Another serine/threonine phosphatase, PP1, that also dephosphorylates Chk1 did not show an increase in protein levels following UV treatment (Fig. 3A). 
Figure 3. PPM1D inhibits phosphorylation of Chk1 and Chk1 targets in cells. (A) Time course of PPM1D protein expression following UV irradiation. U2OS cells were transfected with empty vector and were UV radiated at $30 \mathrm{~J} / \mathrm{m}^{2}$. Cell lysates were harvested at varying time points $(0-24 \mathrm{~h})$ after UV treatment and subjected to Western blot probing with anti-PPM1D and anti-PP1 antibody. (B) PPM1D inhibits Chk1 phosphorylation in cells following UV irradiation. U2OS cells were untransfected or transfected with wild-type PPM1D or phosphatase-dead (PD) constructs or with PPM1D siRNA, then UV irradiated and harvested before or at varying time points after UV treatment. Lysates were Western blot probed with antibodies to Chk1 protein and Chk1 phospho-Ser 345 and phospho-Ser 317. (C) Phosphorylation of downstream Chk1 targets is inhibited by PPM1D. Lysates from U2OS cells were transfected, UV irradiated or unirradiated as in $B$, and analyzed by Western blot for Cdc2 Tyr 15, Cdc 2 protein, CDC25C phospho-Ser 216, and CDC25C protein. (D) Breast cancer cells with amplified PPM1D exhibit attenuated UV-induced Chk1 phosphorylation. Control cell lines (HEK and U2OS) and breast cancer cell lines with amplified PPM1D
A

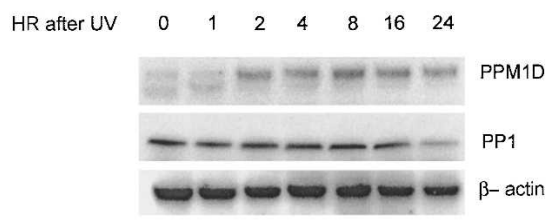

B

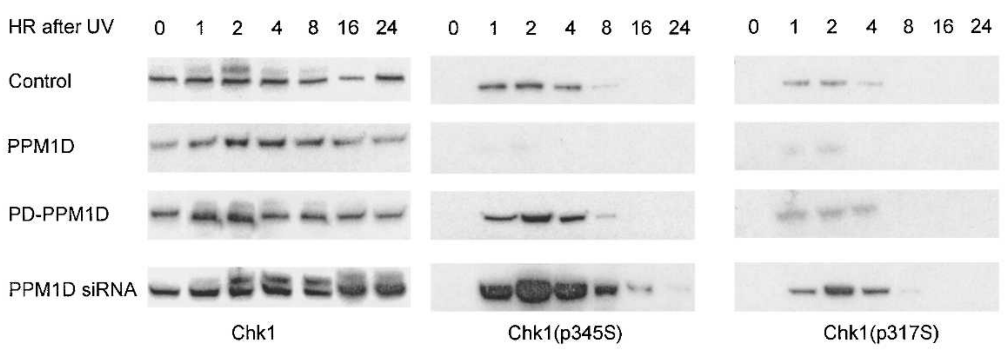

C

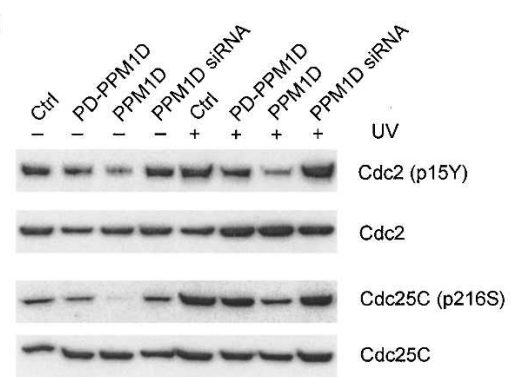

D

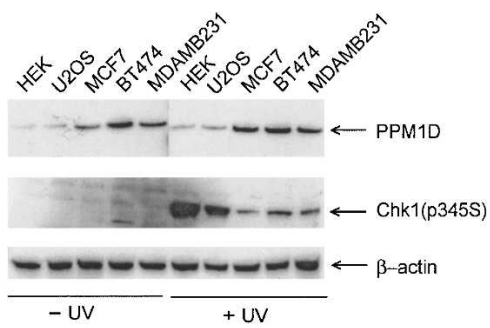

(MCF-7, BT474, and MDAMB231) were unirradiated or UV irradiated $\left(30 \mathrm{~J} / \mathrm{m}^{2}\right)$, and lysates were harvested $2 \mathrm{~h}$ later, prior to Western blot probing with antibodies to PPM1D and Chk1 phospho-Ser 345.

To test whether PPM1D affects Chk1 phosphorylation status in an intact cell, we treated U2OS cells with UV radiation and measured the accumulation of Chk1 protein and Ser 317 and Ser 345 phosphorylated Chk1 at varying time points post-irradiation. Normal cells exhibit a slight transient increase in Chk1 protein levels early after UV treatment (Fig. 3B, left panel). Transfection with PPM1D or phosphatase-dead PPM1D expression constructs have little effect on Chk1 protein levels. However, introduction of PPM1D siRNA into the UVtreated cells results in prolonged increases in Chk1 protein levels after UV irradiation. When phospho-Ser 345 of Chk1 was assessed, U2OS cells treated with UV displayed increased levels of phospho-Ser 345 (Fig. 3B, middle panel). Transfection of PPM1D eliminated this UV-induced Ser 345 phosphorylation, while transfection of phosphatase-dead PPM1D had a slight enhancing effect. Introduction of two different PPM1D siRNAs resulted in very high levels of phospho-Ser 345 , indicating that PPM1D is likely to be a primary phosphatase that dephosphorylates Chk1 at Ser 345 following UV irradiation. When the effects of PPM1D on UV-induced phosphorylation of Chk1 at Ser 317 were examined, the results were less dramatic, but overexpression of PPM1D still resulted in decreased phospho-Ser 317-Chk1, and reduction of PPM1D by PPM1D siRNA resulted in marginally increased phospho-Chk1 (Fig. 3B, right panel).

Chk1 regulates the G2/M checkpoint by phosphory- lating a number of downstream targets, including CDC25C at Ser 216 (Sanchez et al. 1997). To test whether altered PPM1D levels affect not only Chk1, but its downstream targets, we examined phosphorylation of Ser 216 of CDC25C in unirradiated and UV-irradiated cells. Overexpressed PPM1D resulted in reduced Ser 216 phosphorylation and siRNA for PPM1D-induced marginal increases in phospho-Ser 216 (Fig. 3C). We also examined whether a critical mediator of the G2/M-phase transition, Cdc2, showed differential phosphorylation of Tyr 15, an inhibitory phosphorylation site associated with the G2/M checkpoint (Parker and Piwnica-Worms 1992). In the presence of increased PPM1D, Tyr 15 showed decreased phosphorylation following UV irradiation, while reduction of PPM1D increased the inhibitory tyrosine phosphorylation (Fig. 3C). Thus, PPM1D may play a key role in regulating G2/M checkpoint pathways.

Amplification and overexpression of PPM1D has been demonstrated in breast cancers and other cancer types (Bulavin et al. 2002b; Li et al. 2002; Hirasawa et al. 2003; Saito-Ohara et al. 2003). To determine whether the increased PPM1D in cancer cells affects UV-induced Chk1 phosphorylation, we examined Chk1 phospho-Ser 345 levels in untreated and UV-treated cells from three breast cancer cell lines containing amplified PPM1D genes (Bulavin et al. 2004). The three breast cancer lines, MCF-7, BT474, and MDAMB231, showed higher levels of PPM1D protein compared with two control cell lines, 
human embryonic kidney (HEK) cells and U2OS osteosarcoma cells (Fig. 3D). UV treatment resulted in very high levels of Chk1 Ser 345 phosphorylation in the control cell lines, but only a modest induction of Ser 345 phosphorylation in the three cell lines with PPM1D amplification (Fig. 3D). These results suggest that cancers overexpressing PPM1D are likely to have abrogated Chk1-controlled checkpoints.

\section{PPM1D dephosphorylates $p 53$ at Ser 15}

Previously, we had observed that PPM1D null MEFs exhibited slightly higher levels of p53 Ser 15 phosphorylation than wild-type MEFs in unstressed conditions (Choi et al. 2002). p53 Ser 15 is phosphorylated by ATM and ATR in response to IR and UV irradiation (Banin et al. 1998; Canman et al. 1998; Tibbetts et al. 1999). To address whether PPM1D directly dephosphorylates this site, a p53 Ser 15 phosphopeptide was incubated with purified PPM1D in an in vitro phosphatase reaction. PPM1D showed high levels of Ser 15 dephosphorylation that was magnesium dependent and okadaic acid independent (Fig. 4A). Interestingly, when we examined PP1 phosphatase activity on the p53 Ser 15 phosphopeptide, it showed no significant activity, in contrast to its ability to target the Chk1 Ser 345 phosphopeptide (Fig. 4B). When intact phospho-p53 was incubated with increasing amounts of PPM1D, phospho-Ser 15 levels were decreased, while phospho-Ser 46, another stress-induced phosphorylation site on p53, showed no reduction in phosphorylation levels (Fig. 4C).

To determine whether PPM1D affected damage-induced phosphorylation of p53 Ser 15 in vivo, we examined Ser 15 phosphorylation status in IR-treated

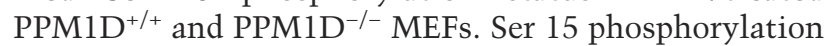
levels were much higher in PPM1D null fibroblasts than in wild-type fibroblasts following IR treatment (Fig. 4D). In addition, while IR induced phosphorylation of Chk1 at Ser 345, this phosphorylation was greatly increased in

\section{A}

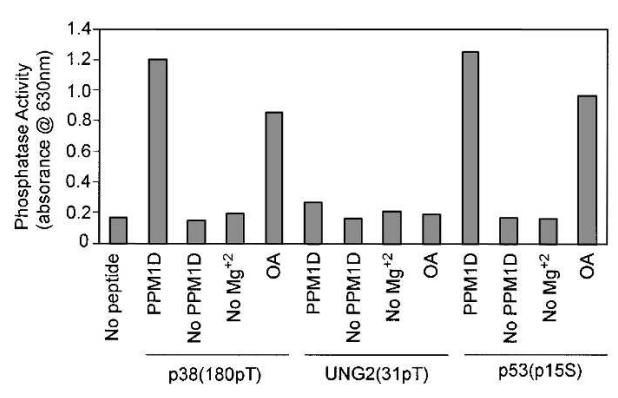

C

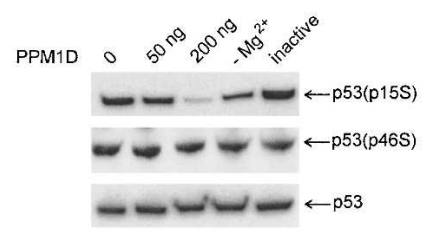

E

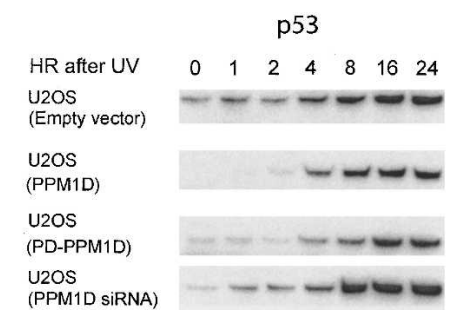

B

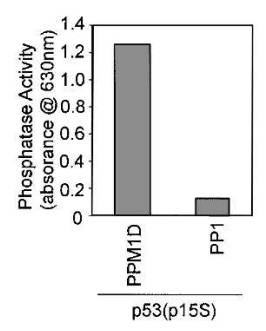

(2)

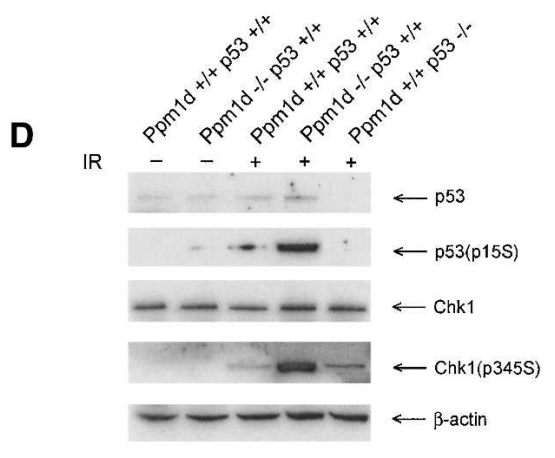

Figure 4. p53 Ser 15 is dephosphorylated by PPM1D. (A) PPM1D dephosphorylates p53 Ser 15 phosphopeptide in vitro. p53 Ser 15 phosphopeptide was incubated with purified PPM1D in an in vitro phosphatase assay. Reactions were also performed in the absence of magnesium or peptide or in the presence of okadaic acid. Positive (p38 $180 \mathrm{pT}$ ) and negative (UNG2 31pT) control phosphopeptides were also assessed for PPM1D activity. (B) PPM1D, but not PP1, has in vitro phosphatase activity on the p53 Ser 15 phosphopeptide. Assay conditions were similar to those in panel $A$. (C) PPM1D dephosphorylates intact p53 at Ser 15. Immunopurified p53 from UV-irradiated U2OS cells was incubated with PPM1D in an in vitro phosphatase assay and was Western blot probed with antibodies to p53 phospho-Ser 15, p53 phospho-Ser 46, and p53 protein. (D) PPM1D null fibroblasts exhibit increased p53 Ser 15 phosphorylation after IR. Lysates harvested from mouse embryo fibroblasts of the designated PPM1D and p53 genotypes $2 \mathrm{~h}$ after treatment with 5 Gy IR were Western blot probed with antibodies to p53 protein (first panel), p53 phospho-Ser 15 (second panel), Chk1 protein (third panel), Chk1 phospho-Ser 345 (fourth panel), and $\beta$-actin (fifth panel). (E) PPM1D inhibits p53 phosphorylation at Ser 15 in UV-treated cells. U2OS cells were untransfected or transfected with wild-type PPM1D or phosphatase-dead (PD) PPM1D or PPM1D siRNA, then UV or mock irradiated and harvested before or at varying times after $30 \mathrm{~J} / \mathrm{m}^{2} \mathrm{UV}$ treatment. Cell lysates were Western blot probed with antibodies to $\mathrm{p} 53$ protein (left panel), p53 phospho-Ser 15 (center panel), or $\beta$-actin (right panel). 
the PPM1D null MEFs compared with their wild-type PPM1D counterparts (Fig. 4D).

When p53 levels were assessed in UV-irradiated U2OS cells with and without altered levels of PPM1D, p53 protein levels began increasing $\sim 4 \mathrm{~h}$ after UV treatment. Addition of PPM1D modestly decreased p53 protein levels, while removal of PPM1D by siRNA resulted in moderate increases in p53 protein levels (Fig. 4E, left panel). When UV-induced accumulation of p53 phospho-Ser 15 was examined, addition of PPM1D resulted in significant reductions in phospho-Ser 15, while reduction of PPM1D by siRNA resulted in dramatic increases in phospho-Ser 15 (Fig. 4E, middle panel).

\section{PPM1D has no apparent effect on damage-induced activation of ATM and ATR}

Since Chk1 Ser 345 and p53 Ser 15 are both ATM/ATR targets, it is possible that the reduced phosphorylation of these sites associated with PPM1D is in part a result of upstream inactivation of ATM or ATR by PPM1D. If PPM1D reduces ATM or ATR activation, the resulting low levels of phospho-Chk1 and phospho-p53 might be misinterpreted as being caused only by direct dephosphorylation by PPMD. To determine the effects of PPM1D on ATM, we examined the IR-induced phos- phorylation of ATM Ser 1981, which has been shown to be rapidly phosphorylated and activated in response to doses of radiation as low as 0.5 Gy (Bakkenist and Kastan 2003). To facilitate these studies, we transduced U2OS tet on cells /containing a tetracycline/doxycycline-inducible transcriptional activator) with a retroviral vector expressing a Flag-tagged version of PPM1D driven by a tetracycline/doxycycline inducible promoter. As shown in Figure 5A (top panel), in the absence of doxycycline, these U2OS tet on (PPM1D) cells exhibit only low levels of endogenous PPM1D. However, after addition of doxycycline, high levels of Flag-PPM1D are expressed. When the U2OS tet on (PPM1D) cells are treated with 5 Gy IR in the absence of doxycycline, phosphorylation of Chk1 Ser 345 is dramatically increased, while in the presence of doxycline, Chk1 Ser 345 is only modestly increased compared with unirradiated cells, suggesting that the induced Flag-PPM1D in these cells is dephosphorylating phospho-Ser 345 (Fig. 5A, second panel). When we assessed phosphorylation of ATM Ser 1981, we found that IR increased phosphorylation at this site, as expected, but that high levels of PPM1D in the doxycyclinetreated, IR-treated cells did not reduce ATM phospho-Ser 1981 levels (Fig. 5A, fifth panel). Thus, it appears that PPM1D does not affect upstream ATM phosphorylation and activation levels, at least with respect to Ser 1981.

Figure 5. Effects of PPM1D on cellular stress and checkpoint targets. (A) ATM and ATRIP damage-induced post-translational modifications appear to be unaffected by PPM1D. U2OS tet on (PPM1D) cells were incubated with or without doxycycline prior to treatment with $5 \mathrm{~Gy}$ IR (Chk1, ATM, $\beta$-actin panels) or $30 \mathrm{~J} / \mathrm{m} 2$ UV radiation (ATRIP panel). Two hours after irradiation, lysates were harvested and subjected to SDS-polyacrylamide gel electrophoresis and Western blot probing with antibodies to PPM1D (top panel), Chk1 phospho-Ser 345 (second panel), Chk1 protein (third panel), ATM protein (fourth panel), ATM phospho-Ser 1981 (fifth panel), ATRIP protein (sixth panel), and $\beta$-actin (seventh panel). (B) ATR-ATRIP interactions appear to be unaffected by PPM1D. U2OS tet on (PPM1D) cells were incubated with or without doxycycline and mock treated or treated with $30 \mathrm{~J} / \mathrm{m}^{2}$ $\mathrm{UV}$ radiation. Lysates were harvested $2 \mathrm{~h}$ after irradiation and subjected to immunoprecipitation with an anti-ATR antibody followed by Western blotting with antibodies to ATR (top panel) or ATRIP (bot-

A

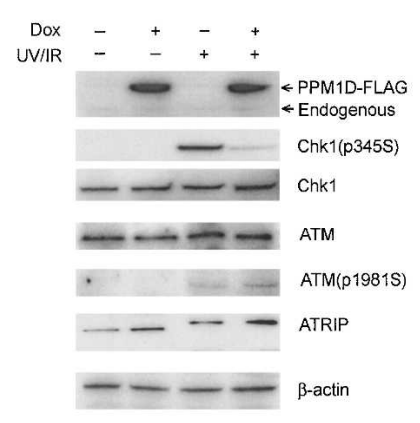

C

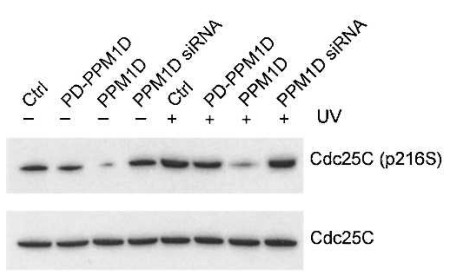

B

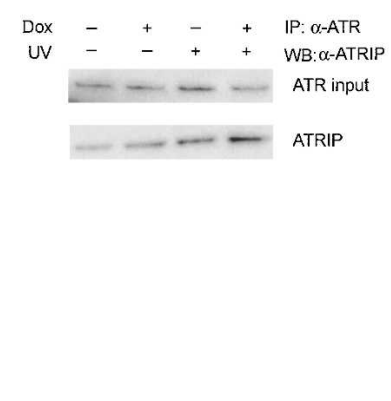

D

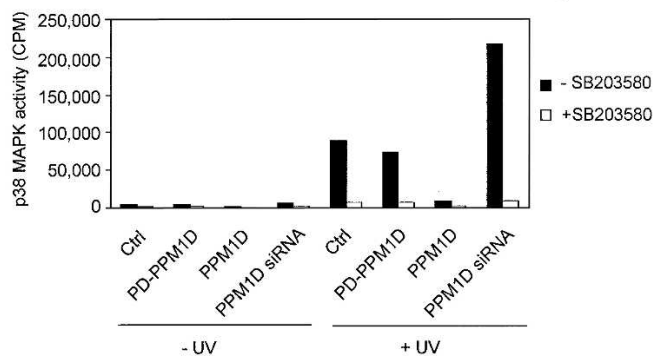

tom panel). (C) PPM1D overexpression leads to CDC25C dephosphorylation in the absence of p38 MAP kinase signaling. U2OS cells were incubated in the presence of the p38 MAP kinase inhibitor SB203580 and transfected with empty vector, phosphatase-dead PPM1D, wild-type PPM1D, or PPM1D siRNA prior to UV or mock treatment. Lysates were immunoprecipitated with antibody specific to the Ser 216 phosphorylated form of CDC25C. (D) MAP kinase inhibitor SB203580 completely abrogates p38 MAP kinase activity. U2OS cells were transfected and UV or mock treated as in panel $A$ and lysates were measured for p38 activity by assessment of p38 target MAPKAP-K2 kinase activity on a target peptide. 
We also examined ATR and ATRIP interactions in response to UV irradiation. Damage-induced activation of ATR results in formation of a ATR-ATRIP complex (Zou and Elledge 2003) and ATR-dependent phosphorylation of ATRIP (Itakura et al. 2004). We found that following UV irradiation, ATRIP undergoes a mobility shift consistent with damage-induced phosphorylation (Fig. 5A, sixth panel). Increased expression of PPM1D appears to have no effect on the mobility of this damage-induced ATRIP shift, suggesting that it does not dephosphorylate ATRIP. Moreover, immunoprecipitation Western blot analyses of U2OS tet on (PPM1D) cells with and without doxycycline and UV show a slight enhancement of ATRIP binding to ATR following radiation, but no effects of PPM1D on this binding (Fig. 5B). Thus, the preliminary evidence suggests that PPM1D affects ATM/ ATR targets Chk1 and p53, but has minimal effects on ATM or ATR activation itself.

\section{PPM1D may suppress G2/M checkpoints}

\section{in the absence of p38 MAP kinase signaling}

PPM1D has previously been shown to dephosphorylate and inactivate p38 MAP kinase, an important stress response kinase (Takekawa et al. 2000). In addition, p38 has been shown to regulate UV-induced G2/M checkpoints in part through phosphorylation of CDC25B and CDC25C (Bulavin et al. 2001). One possibility is that the checkpoint abrogation activities of PPM1D are largely dependent on its inactivation of p38 rather than ATM/ ATR targets (Bulavin et al. 2002a). To test this possibility, we treated U20S cells with SB203580, a known inhibitor of p38 MAP kinase, and examined phosphorylation of CDC25C, a G2/M checkpoint control protein, in the presence of overexpressed PPM1D. PPM1D suppressed phosphorylation in the presence of SB203580, suggesting that PPM1D can inhibit CDC25C-mediated checkpoint regulation under reduced p38 signaling conditions (Fig. 5C). We confirmed that p38 activation was completely inhibited by SB203580 by measuring p38 MAP kinase activity in the presence and absence of the drug (Fig. 5D). These results are consistent with findings by Bulavin et al. (2001) that inhibition of p38 signaling after UV treatment does not result in reduction of 14-3-3 binding specific for phosphorylated Ser 216 on CDC25C.

\section{Abrogation of the intra-S-phase checkpoint by PPM1D}

ATM/ATR, Chk1, and p53 are important mediators of cell cycle checkpoints (Sancar et al. 2004). Since these checkpoint regulators are activated by phosphorylation events, dephosphorylation of these proteins by PPM1D might reverse the checkpoint activation effect. Consistent with this scenario, we have previously shown that PPM1D null MEFs have an augmented G1 arrest response to IR (Choi et al. 2002). To examine the effects of PPM1D on cell cycle checkpoints, we mock treated or treated U2OS tet on (PPM1D) cells with ultraviolet and ionizing radiation and performed cell cycle checkpoint assays in the presence or absence of doxycycline or in the presence or absence of transfected PPM1D siRNA. To specifically examine the effects of PPM1D on the intraS-phase checkpoint, we incubated U2OS tet on (PPM1D) cells in ${ }^{14} \mathrm{C}$-thymidine for $24 \mathrm{~h}$, irradiated the cells with $5 \mathrm{~J} / \mathrm{m}^{2} \mathrm{UV}$ or 3 Gy IR, and then incubated the cells for varying times $(0.5-48 \mathrm{~h})$ prior to pulse labeling the cells with ${ }^{3} \mathrm{H}$-thymidine for $15 \mathrm{~min}$. Cells were then harvested, fixed, and assessed for tritium incorporation as a marker for S-phase activity. As expected, UV-irradiated control cells (no doxycycline, control siRNA) showed decreased thymidine incorporation that bottomed at $16 \mathrm{~h}$ post-treatment and then recovered to normal levels by $48 \mathrm{~h}$. UV irradiation decreased thymidine incorporation $\sim 50 \%$ compared with unirradiated cells (Fig. 6A). In UVirradiated cells in the presence of doxycycline (and control siRNA), overexpression of PPM1D resulted in a relatively modest $25 \%$ reduction in incorporation at $24 \mathrm{~h}$
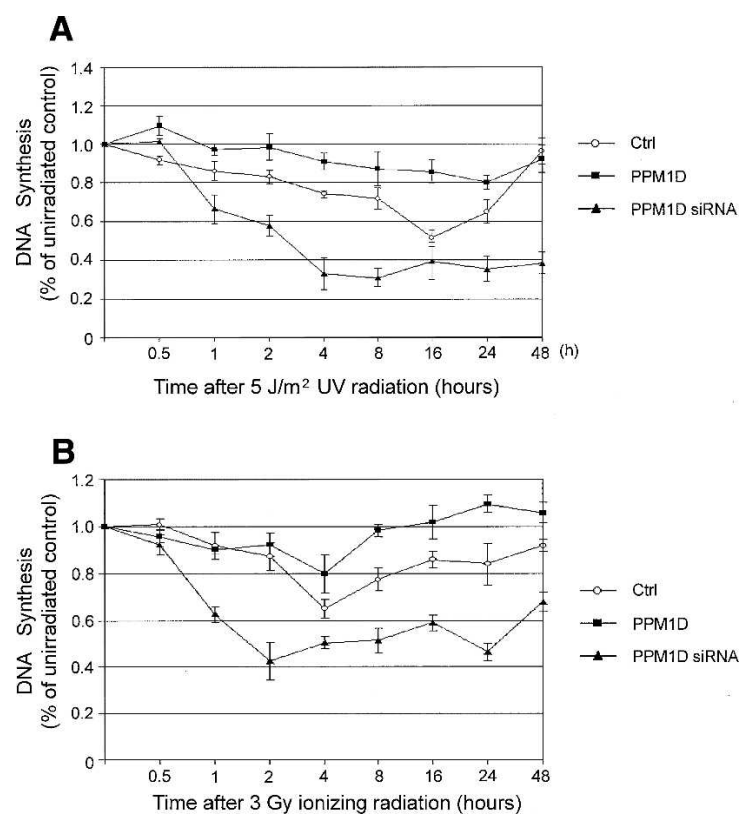

Figure 6. PPM1D abrogates the intra-S-phase checkpoint in response to UV and IR. (A) PPM1D inhibits the intra-S checkpoint in response to UV radiation. U2OS tet on (PPM1D) cells were irradiated with $5 \mathrm{~J} / \mathrm{m}^{2} \mathrm{UV}$ radiation, incubated for varying lengths of time $(0.5-48 \mathrm{~h})$, pulse labeled with ${ }^{3} \mathrm{H}$-thymidine for $15 \mathrm{~min}$, and harvested, and cell lysates were measured for ${ }^{3} \mathrm{H}$ thymidine incorporation compared with unirradiated control cells. The cells were either maintained under normal conditions in the absence of doxycycline after transfection with control siRNA (Ctrl, circles), under PPM1D overexpression conditions in the presence of doxycycline and control siRNA (PPM1D, squares), or under reduced PPM1D expression (without doxycycline) after transfection of PPM1D siRNA (PPM1D siRNA, triangles). Values are expressed as relative incorporation of ${ }^{3} \mathrm{H}$ thymidine compared with mock irradiated control cells. (B) PPM1D inhibits the intra-S-phase checkpoint in response to IR. The experiments were carried out exactly as in panel $A$, except that all cells were treated with 3 Gy IR instead of UV radiation. 
post-UV treatment. Inhibition of PPM1D by treatment of U2OS tet on (PPM1D) cells (without doxycycline) with PPM1D siRNA resulted in a much lower thymidine incorporation that was maximal only $4 \mathrm{~h}$ post-UV and reached levels of $70 \%$ reduction that continued even at $48 \mathrm{~h}$ post-irradiation. Intra-S-phase checkpoint assays performed at a higher dosage of UV irradiation $\left(30 \mathrm{~J} / \mathrm{m}^{2}\right)$ at 3 and $8 \mathrm{~h}$ post-irradiation also showed PPM1D attenuation of the checkpoint (data not shown). Thus, increased levels of PPM1D significantly attenuate the UVinduced intra-S-phase checkpoint, while reduced PPM1D levels dramatically enhance and prolong the intra-S-phase checkpoint.

We also examined the effects of 3 Gy IR on the intraS-phase checkpoint in the U2OS tet on (PPM1D) cells. The observed results were similar to those observed for UV treatment. Control cells expressing normal levels of PPM1D exhibited a maximal $35 \%$ reduction of thymidine incorporation by $4 \mathrm{~h}$ post-irradiation that did not fully return to normal by $48 \mathrm{~h}$ (Fig. 6B). PPM1D overexpressing cells showed a maximal $20 \%$ reduction in thymidine incorporation by $4 \mathrm{~h}$ that rapidly returned to normal by $8 \mathrm{~h}$ post-irradiation. In contrast, reduction of PPM1D levels by PPM1D siRNA transfection displayed a $58 \%$ reduction by $2 \mathrm{~h}$ post-irradiation and incorporation levels remained low for up to 48 h. Thus, PPM1D levels play an important role in regulating the intra-Sphase checkpoint in response to both ultraviolet and ionizing radiation.

\section{Abrogation of the G2/M checkpoint by PPM1D}

To assess the G2/M checkpoint effects of PPM1D, we mock treated or treated U2OS tet on (PPM1D) cells with doxycycline or PPM1D siRNA, followed by treatment with $5 \mathrm{~J} / \mathrm{m}^{2} \mathrm{UV}$. At varying time points after irradiation, the cells were fixed and analyzed by flow cytometry for DNA content and phospho-histone H3 content. Phospho-histone $\mathrm{H} 3$ is a marker for cells in mitosis and an effective G2/M checkpoint response will prevent cells from entering $M$ phase. UV treatment reduced the number of control cells (no doxycycline, control siRNA) in mitosis by $\sim 70 \%$ compared with their unirradiated counterparts by $8 \mathrm{~h}$ post-irradiation (Fig. 7A). Overexpression of PPM1D in UV-treated cells delayed and attenuated the reduction in $\mathrm{M}$-phase cells with a maximal reduction of only $30 \%$ by $16 \mathrm{~h}$ post-irradiation. Reduction of PPM1D by PPM1D siRNA produced a more pronounced G2/M block with an $85 \%$ reduction in M-phase cells by $8 \mathrm{~h}$, which remained reduced up to $48 \mathrm{~h}$. Thus, it appears that PPM1D overexpression attenuates the G2/M checkpoint, while reduction of PPM1D exacerbates and prolongs the G2/M checkpoint.

Examination of the effects of PPM1D on the IRinduced G2/M checkpoint gave results similar to those observed for the UV experiments. Cells with normal levels of PPM1D showed a maximal $85 \%$ reduction in mitotic cells by $4 \mathrm{~h}$ after 3 Gy irradiation (Fig. 7B). Cells with overexpressed PPM1D exhibited a less robust
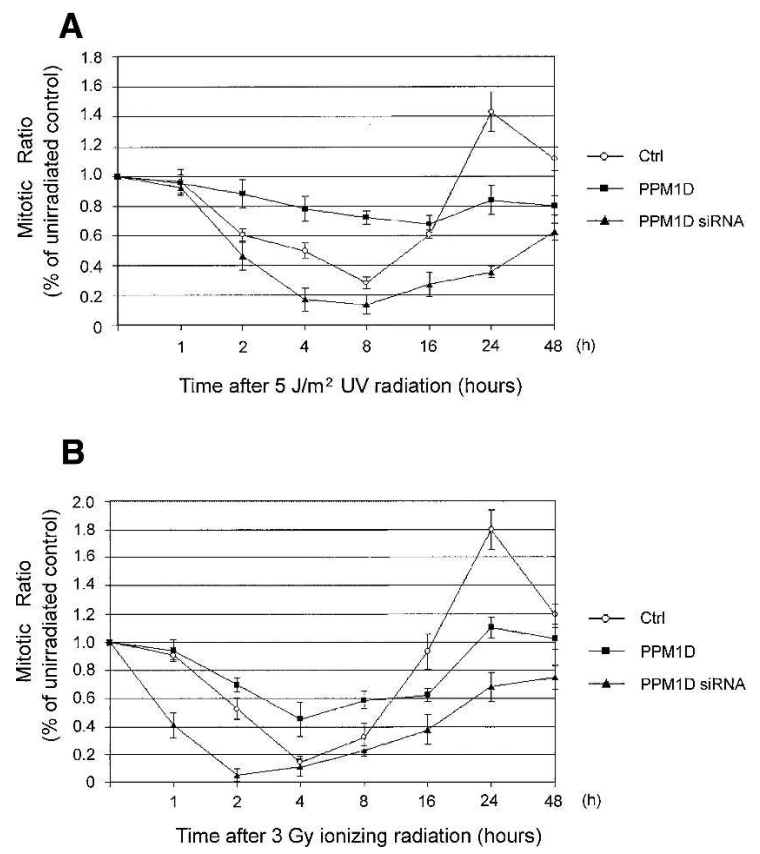

Figure 7. PPM1D abrogates the G2/M checkpoint in response to UV and IR. (A) PPM1D inhibits the G2/M checkpoint in response to UV radiation. U2OS tet on (PPM1D) cells were irradiated with $5 \mathrm{~J} / \mathrm{m}^{2} \mathrm{UV}$ radiation, incubated for varying lengths of time (0.5-48 h), harvested, fixed, and incubated with antiphosphohistone H3 antibody, followed by FITC-conjugated secondary antibody and fluorescence measurement by flow cytometry. The cells were maintained under normal conditions in the absence of doxycycline after transfection with control siRNA (Ctrl, circles), under PPM1D overexpression conditions in the presence of doxycycline and control siRNA (PPM1D, squares), or under reduced PPM1D expression (without doxycycline) after transfection of PPM1D siRNA (PPM1D siRNA, triangles). Values are expressed as relative phosphohistone $\mathrm{H} 3$ fluorescence compared with mock irradiated control cells. (B) PPM1D inhibits the G2/M-phase checkpoint in response to IR. The experiments were carried out exactly as in panel $A$, except that all cells were treated with 3 Gy IR instead of UV radiation.

G2/M checkpoint response, with a maximal 55\% reduction in mitotic cells by $4 \mathrm{~h}$ post-irradiation. Finally, the cells with reduced PPM1D displayed an enhanced 95\% reduction in $\mathrm{M}$-phase cells as early as $2 \mathrm{~h}$ post-irradiation and the M-phase reduction was prolonged. Thus, PPM1D abrogates the G2/M checkpoint in response to both ionizing and UV radiation.

\section{Discussion}

Initiation of the DNA damage response and engagement of cell cycle checkpoints are critical for protecting the cell from propagation of damaged DNA templates (Sancar et al. 2004). ATM and ATR clearly play an important role in initiating and propagating the signaling pathways that mediate cell cycle checkpoints and DNA damage repair through their ability to phosphorylate an array of 
critical target proteins (Shiloh 2003). Once the cell is arrested and the DNA damage is repaired, a mechanism to return the cell to a homeostatic state must exist. To achieve such a homeostatic state, those ATM/ATR targets that are activated through phosphorylation may have to be inactivated through dephosphorylation. Based on the data presented in this paper, we propose that PPM1D may contribute to reversing the effects of the ATM/ATR-mediated activation through dephosphorylation of Chk1 and p53 following DNA damage. Consistent with this is the fact that PPM1D dephosphorylates ATM/ATR target sites at Chk1 Ser 345 and p53 Ser 15.

The correlation between ATM/ATR phosphorylation and PPM1D dephosphorylation is not perfect, since PPM1D did not efficiently dephosphorylate Chk1 at Ser 317, while ATM and ATR phosphorylate that site. Thus, other phosphatases may play an important role in reversing ATM/ATR phosphorylation events. Recently, phosphatases such as protein phosphatase 5 (PP5) and PP1 have emerged as alternative candidates that may reverse ATM/ATR phosphorylation effects (Ali et al. 2004; Bakkenist and Kastan 2004b; Den Elzen et al. 2004), while PP2A could assist in activating ATM (Goodarzi et al. 2004). We confirmed here that human PP1 does target both Ser 317 and Ser 345 for dephosphorylation (Fig. 2B; data not shown). However, PP1 protein levels are not induced following DNA damage (though its phosphatase activity could be increased by damage). In contrast, we show that PPM1D protein levels and possibly its posttranslational modification state are altered in cells incurring DNA damage. This confirms and extends previous data showing that PPM1D mRNA was up-regulated in a p53-dependent manner following UV, IR, and other DNA damaging agents. The accumulation of PPM1D appears to take at least several hours, allowing sufficient time for DNA damage to be repaired prior to PPM1Dmediated relaxation of the cell cycle checkpoints. The delayed PPM1D up-regulation, its dependence on stressresponsive wild-type p53, its checkpoint abrogation activity, and the two PPM1D targets identified here as ATM/ATR substrates support the conclusion that PPM1D is an inhibitor of some ATM/ATR stress response pathways. Importantly, this inhibition by PPM1D did not appear to extend to ATM or ATR itself, since these two damage response initiators seemed to be unaffected in aspects of their activation by increased levels of PPM1D. Thus, PPM1D may be specific for some, though not all, of the ATM/ATR target sites on Chk1 and $\mathrm{p} 53$.

The specific targets of PPM1D are of interest. The highly conserved phosphatase domain of PPM1D directly interacts with Chk1. Moreover, PPM1D dephosphorylates the ATM target site phospho-Ser 345 on Chk1. Chk1 is a critical mediator of the ATM/ATR signal and phosphorylates key cell cycle effectors such as CDC25A and CDC25C to facilitate S-phase and G2/M checkpoints (Bartek and Lukas 2003). Moreover, phosphorylation of Ser 345 has been shown to be important for Chk1 activation in response to genotoxic stress and for nuclear retention after DNA damage (Lopez-Girona et al. 2001; Zhao and Piwnica-Worms 2001; Jiang et al. 2003). Mutation of Ser 345 to alanine prevents Chk1 from increasing its kinase activity in response to genotoxic stress (Capasso et al. 2002), consistent with our findings that in vitro PPM1D did inhibit Chk1 phosphorylation of a CDC25C target peptide. We hypothesize that PPM1D binding to Chk1 and dephosphorylation of Ser 345 may be a primary mechanism of Chk1 kinase inhibition. Overexpression of PPM1D in vivo is correlated with reduced Chk1 kinase activity on key substrates such as CDC25C and appears to modestly reduce Chk1 stability. We have shown that increased PPM1D levels are also associated with reduced inhibitory phosphorylation of the mitotic kinase Cdc2 and with abrogation of intra-S and G2/M checkpoints following UV and ionizing irradiation. Conversely, removal of PPM1D through siRNA results in more robust intra-S and G2/M checkpoints. Thus, PPM1D may abrogate cell cycle checkpoints in part through its effects on Chk1.

Evidence was presented here that PPM1D dephosphorylates p53 at Ser 15. Unlike Chk1, however, we have no evidence that PPM1D can directly bind to p53 (X. Lu, unpubl.). ATM/ATR-induced phosphorylation at this site may inhibit MDM2-p53 interactions, thus inhibiting MDM2-mediated proteolytic degradation of p53 (Shieh et al. 1997; Maya et al. 2001). Recent data indicate that Ser 15 phosphorylation by ATM/ATR is critical for activating p53 apoptotic function (Sluss et al. 2004). PPM1D may contribute to p53 deactivation directly by dephosphorylating the ATM/ATR phosphorylated Ser 15 , and indirectly through decreased Chk1 phosphorylation of Ser 20, which could facilitate p53 degradation by MDM2. Thus, PPM1D may be part of a p53 negative feedback regulatory loop in which damage activated ATM/ATR phosphorylates p53 at Ser 15. Phosphorylated p53 is more active and up-regulates PPM1D expression. Accumulation of PPM1D reverses p53 activation by dephosphorylation of p53, completing the feedback loop.

The ATM and ATR kinases have a specificity for targets containing an S/TQ motif (Kim et al. 1999). The discovery that such sites can be dephosphorylated by PPM1D was initially surprising, since the only two previously described phosphorylation site motifs dephosphorylated by PPM1D are quite different. PPM1D has been shown to dephosphorylate p38 MAP kinase and uracil DNA glycosylase at the phosphothreonine of dual phosphorylated TXY motifs (Takekawa et al. 2000; Lu et al. 2004). This suggests that PPM1D may have multiple sequence specificities in its target sites and can dephosphorylate substrates of both the ATM/ATR and MAP kinase stress response pathways. We are currently investigating other dephosphorylation targets for PPM1D to determine the extent of PPM1D specificity in modulating stress response signaling.

The abrogation of cell cycle checkpoints and inactivation of the tumor suppressor p53 by PPM1D has oncogenic implications for this phosphatase. PPM1D acts as an oncogene in transformation assays and its amplification and overexpression in breast cancers and other tumor types supports its oncogenic role (Bulavin et al. 
2002b; Li et al. 2002; Hirasawa et al. 2003; Saito-Ohara et al. 2003). The previously described inactivation of p53 via p38 was an indirect mechanism. Here, we show that p53 activity is likely to be directly affected by PPM1D dephosphorylation of p53 at Ser 15. Moreover, the dephosphorylation of the Chk1 cell cycle checkpoint protein by PPM1D may have a powerful effect in promoting oncogenesis. By abrogating cell cycle checkpoints, PPM1D overexpression would likely result in increased proliferation and chromosomal instability. By inhibiting the DNA damage response, PPM1D overexpression could result in increased accumulation of mutations, not only through abrogation of checkpoint control proteins, but also through direct suppression of DNA repair. In a previous study, we have shown that PPM1D suppresses DNA base excision repair, and recent studies in our laboratory indicate that it may also inhibit nucleotide excision repair (Lu et al. 2004; T.A. Nguyen, unpubl.). Thus, PPM1D merits further study to elucidate its effects on DNA damage responses, cell cycle checkpoint regulation, and cancer.

\section{Materials and methods}

\section{Cells}

For most experiments, the U2OS cell line was used. This is a wild-type p53-containing human osteosarcoma line. Results obtained in U2OS cells were often confirmed in p53 null

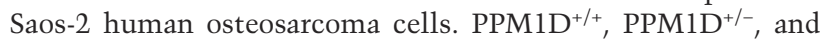
PPM1D $^{-/-}$mouse embryo fibroblasts and human embryonic kidney cells were also utilized for confirmatory experiments. Culture conditions were as previously described (Choi et al. 2002; Lu et al. 2004).

\section{Generation of U2OS Tet-on (PPM1D) cells}

PPM1D cDNA tagged with Flag was inserted into the BamH1 site in pRevTRE vector (BD Biosciences, catalog \#631002). Together with retroviral packaging plasmids pVSVG and pHit60, pRexTRE-PPM1D was transfected into 293T cells to generate retroviral vectors containing Flag-PPM1D. U2OS Tet-on cells (BD Biosciences, catalog \#630919) were infected with the above retrovirus, then screened with $400 \mu \mathrm{g} / \mathrm{mL}$ of hygromycin. Twelve hygromycin-resistant positive colonies were isolated, amplified, and checked for inducible expression of Flag-PPM1D protein following addition of $0.5 \mu \mathrm{g} / \mathrm{mL}$ doxycycline (BD Biosciences, catalog \#631311) individually. Clonal lines with high levels of inducible PPM1D expression and nondetectable basal levels of Flag-PPM1D in the absence of doxycycline were used for the experiments described in this paper.

\section{Plasmids and siRNA}

Wild-type and mutant PPM1D plasmids used in these experiments have been previously described (Lu et al. 2004). The phosphatase-dead PPM1D point mutant D307A is catalytically inactive in in vitro and in vivo phosphatase reactions ( $\mathrm{Lu}$ et al. 2004). The Chk1 expression vector was obtained from Origene. The PPM1D siRNA has also been previously described (Lu et al. 2004).

\section{Immunoprecipitations and Western blot analyses}

Immunoprecipitations, Western blot analysis, and immunoprecipitation Westerns were performed by standard methods and have been described previously (Lu et al. 2004). Antibodies were obtained from commercial sources. These are listed below.

\section{Antibodies and purified proteins}

Anti-GST (\#05-311), anti-Histone H3(p10S), and anti-Chk1 (\#06-965) were purchased from Upstate; anti-Chk1(p317S) (\#2344), anti-Chk1(p345S) (\#2341), anti-Cdc2 (\#9112), antiCdc2(p15Y) (\#9111), anti-CDC25C (\#9522), anti-CDC25C(pS216) (\#9528), anti-p53 (\#9282), anti-p53(p15S) (\#9286), and antip53(p46S) (\#2521) were purchased from Cell Signaling Technology; anti-PPM1D (\#2380-MC-100) was purchased from Trevigen; HRP-anti-mouse IgG (\#2380) and HRP-anti-rabbit IgG (\#2379) were purchased from Santa Cruz; FITC-anti-rabbit IgG (\#111-095-093) was purchased from Jackson ImmunoReseach Laboratories. Anti-PP1 antibody was purchased from Upstate. Anti-MAPKAP-K2 (catalog \#3042) was provided by Cell Signaling. Purified PP1 (\#539493), PP2A (\#539508), and PP2B (\#539568) were obtained from Calbiochem. PP2C $\alpha(\# 14-218)$ is from Upstate.

\section{In vitro phosphatase and kinase assays}

The in vitro phosphatase assays have been described previously (Lu et al. 2004). The Chk1 in vitro kinase assay components were obtained from Upstate and the assay was performed according to the manufacturer's specifications. The p38 MAP kinase assay kit (\#14-216) is from Upstate and was used according to the manufacturer's instructions. Phosphopeptides for the in vitro phosphatase assays are listed below.

\section{Phosphopeptides}

All the phosphopeptides were custom synthesized by New England Peptide. The sequences are UNG2(31pT), Ac-A-V-Q-G(pT)-G-V-A-G-V-amide; Chk1(317pS), Ac-V-K-Y-S-S-(pS)-Q-P-EP-R-amide; Chk1(345pS), Ac-Q-G-I-S-F-(pS)-Q-P-T-C-P-amide; P53(15pS), Ac-V-E-P-P-L-(pS)-Q-E-T-F-S-amide.

\section{Cell cycle checkpoint assays}

The intra-S-phase checkpoint assay was performed essentially as described by $\mathrm{Xu}$ et al. (2002). Briefly, cells were prelabeled with $10 \mathrm{nCi} / \mathrm{mL}$ of $\left[{ }^{14} \mathrm{C}\right]$ thymidine (Amersham Biosciences) for $24 \mathrm{~h}$. Cells were irradiated and incubated for the time indicated and pulse-labeled with $2.5 \mu \mathrm{Ci}$ of $\left[{ }^{3} \mathrm{H}\right]$ thymidine (Amersham Biosciences) for $15 \mathrm{~min}$. Cells were harvested at various time points after irradiation and fixed with $70 \%$ methanol. The account of radioactivity was assayed in a liquid scintillation counter. ${ }^{3} \mathrm{H}$ counts were normalized with ${ }^{14} \mathrm{C}$ counts. The G2/ $\mathrm{M}$-phase checkpoint assays were performed as previously described (Xu et al. 2002). Cells were harvested at indicated times after irradiation, washed with phosphate-buffered saline (PBS), and fixed in suspension by the addition of $2 \mathrm{~mL} 70 \%$ ethanol. After fixation, the cells were washed twice with PBS, suspended in $1 \mathrm{~mL} 0.25 \%$ Triton X-100 in PBS, and incubated on ice for $15 \mathrm{~min}$. After centrifugation, the cell pellet was suspended in $100 \mu \mathrm{L}$ of PBS containing $1 \%$ bovine serum albumin (BSA) and $1.0 \mu \mathrm{g}$ of a polyclonal antibody that specifically recognizes the phosphorylated form of histone $\mathrm{H} 3$ (Upstate Biotechnology) and incubated $3 \mathrm{~h}$ at room temperature. Then, the cells were rinsed with PBS containing $1 \%$ BSA and incubated with fluorescein 
isothiocyanate-conjugated goat anti-rabbit IgG antibody (Jackson ImmunoResearch Laboratories) diluted at a ratio of 1:25 in PBS containing $1 \%$ BSA. After a $30-\mathrm{min}$ incubation at room temperature in the dark, the cells were washed again, resuspended in $25 \mu \mathrm{g} / \mathrm{mL}$ propidium iodide (Sigma) and $0.1 \mathrm{mg} / \mathrm{mL}$ RNase A (Sigma) in PBS, and incubated at room temperature for $30 \mathrm{~min}$ before the fluorescence was measured. Cellular fluorescence was measured by flow cytometry.

\section{Ultraviolet and ionizing radiation}

Five joules per square meter of UV radiation and 3 Gy of IR were used in all checkpoint assay experiments.

\section{Acknowledgments}

We thank Konstantin Galaktionov and Thuy-Ai Nguyen for helpful discussions. We also thank Bill Mansfield for technical assistance. This work was supported by a grant from the National Cancer Institute to L.D.

\section{References}

Ali, A., Zhang, J., Bao, S., Liu, I., Otterness, D., Dean, N.M., Abraham, R.T., and Wang, X.F. 2004. Requirement of protein phosphatase 5 in DNA-damage-induced ATM activation. Genes \& Dev. 18: 249-254.

Bakkenist, C.J. and Kastan, M.B. 2003. DNA damage activates ATM through intermolecular autophosphorylation and dimer dissociation. Nature 421: 499-506.

- 2004a. Initiating cellular stress responses. Cell 118: $9-17$.

- 2004b. Phosphatases join kinases in DNA-damage response pathways. Trends Cell Biol. 14: 339-341.

Banin, S., Moyal, L., Shieh, S., Taya, Y., Anderson, C.W., Chessa, L., Smorodinsky, N.I., Prives, C., Reiss, Y., Shiloh, Y., et al. 1998. Enhanced phosphorylation of p53 by ATM in response to DNA damage. Science 281: 1674-1677.

Bartek, J. and Lukas, J. 2003. Chk1 and Chk2 kinases in checkpoint control and cancer. Cancer Cell 3: 421-429.

Bulavin, D.V., Saito, S., Hollander, M.C., Sakaguchi, K., Anderson, C.W., Appella, E., and Fornace Jr., A.J. 1999. Phosphorylation of human p53 by p38 kinase coordinates $\mathrm{N}$-terminal phosphorylation and apoptosis in response to UV radiation. EMBO J. 18: 6845-6854.

Bulavin, D.V., Higashimoto, Y., Popoff, I.J., Gaarde, W.A., Basrur, V., Potapova, O., Appella, E., and Fornace Jr., A.J. 2001. Initiation of a $G 2 / M$ checkpoint after ultraviolet radiation requires p38 kinase. Nature 411: 102-107.

Bulavin, D.V., Amundson, S.A., and Fornace, A.J. 2002a. p38 and Chk1 kinases: Different conductors for the G(2)/M checkpoint symphony. Curr. Opin. Genet. Dev. 12: 92-97.

Bulavin, D.V., Demidov, O.N., Saito, S., Kauraniemi, P., Phillips, C., Amundson, S.A., Ambrosino, C., Sauter, G., Nebreda, A.R., Anderson, C.W., et al. 2002b. Amplification of PPM1D in human tumors abrogates p53 tumor-suppressor activity. Nat. Genet. 31: 210-215.

Bulavin, D.V., Phillips, C., Nannenga, B., Timofeev, O., Donehower, L.A., Anderson, C.W., Appella, E., and Fornace Jr., A.J. 2004. Inactivation of the Wip1 phosphatase inhibits mammary tumorigenesis through p38 MAPK-mediated activation of the p16(Ink4a)-p19(Arf) pathway. Nat. Genet. 36: 343-350.

Canman, C.E., Lim, D.S., Cimprich, K.A., Taya, Y., Tamai, K., Sakaguchi, K., Appella, E., Kastan, M.B., and Siliciano, J.D. 1998. Activation of the ATM kinase by ionizing radiation and phosphorylation of p53. Science 281: 1677-1679.

Capasso, H., Palermo, C., Wan, S., Rao, H., John, U.P., O'Connell, M.P., and Walworth, N.C. 2002. Phosphorylation activates Chk1 and is required for checkpoint-mediated cell cycle arrest. J. Cell Sci. 115: 4555-4564.

Choi, J., Appella, E., and Donehower, L.A. 2000. The structure and expression of the murine wildtype p53-induced phosphatase 1 (Wip1) gene. Genomics 64: 298-306.

Choi, J., Nannenga, B., Demidov, O.N., Bulavin, D.V., Cooney, A., Brayton, C., Zhang, Y., Mbawuike, I.N., Bradley, A., Appella, E., et al. 2002. Mice deficient for the wild-type p53induced phosphatase gene (Wip1) exhibit defects in reproductive organs, immune function, and cell cycle control. Mol. Cell. Biol. 22: 1094-1105.

Cohen, P. 1989. The structure and regulation of protein phosphatases. Annu. Rev. Biochem. 58: 453-508.

Den Elzen, N.R. and O'Connell, M.J. 2004. Recovery from DNA damage checkpoint arrest by PP1-mediated inhibition of Chk1. EMBO J. 23: 908-918.

Den Elzen, N., Kosoy, A., Christopoulos, H., and O'Connell, M.J. 2004. Resisting arrest: Recovery from checkpoint arrest through dephosphorylation of Chk1 by PP1. Cell Cycle 3: 529-533.

Fiscella, M., Zhang, H., Fan, S., Sakaguchi, K., Shen, S., Mercer, W.E., Vande Woude, G.F., O'Connor, P.M., and Appella, E. 1997. Wip1, a novel human protein phosphatase that is induced in response to ionizing radiation in a p53-dependent manner. Proc. Nat1. Acad. Sci. 94: 6048-6053.

Goodarzi, A.A., Jonnalagadda, J.C., Douglas, P., Young, D., Ye, R., Moorhead, G.B., Lees-Miller, S.P., and Khanna, K.K. 2004. Autophosphorylation of ataxia-telangiectasia mutated is regulated by protein phosphatase 2A. EMBO J. 23: 44514461.

Harrison, M., Li, J., Degenhardt, Y., Hoey, T., and Powers, S. 2004. Wip1-deficient mice are resistant to common cancer genes. Trends Mol. Med. 10: 359-361.

Hirasawa, A., Saito-Ohara, F., Inoue, J., Aoki, D., Susumu, N., Yokoyama, T., Nozawa, S., Inazawa, J., and Imoto, I. 2003. Association of $17 \mathrm{q} 21-\mathrm{q} 24$ gain in ovarian clear cell adenocarcinomas with poor prognosis and identification of PPM1D and APPBP2 as likely amplification targets. Clin. Cancer Res. 9: 1995-2004.

Itakura, E., Umeda, K., Sekoguchi, E., Takata, H., Ohsumi, M., and Matsuura, A. 2004. ATR-dependent phosphorylation of ATRIP in response to genotoxic stress. Biochem. Biophys. Res. Commun. 323: 1197-1202.

Jiang, K., Pereira, E., Maxfield, M., Russell, B., Goudelock, D.M., and Sanchez, Y. 2003. Regulation of Chk1 includes chromatin association and 14-3-3 binding following phosphorylation on Ser-345. J. Biol. Chem. 278: 25207-25217.

Kim, S.T., Lim, D.S., Canman, C.E., and Kastan, M.B. 1999. Substrate specificities and identification of putative substrates of ATM kinase family members. J. Biol. Chem. 274: 37538-37543.

Kyriakis, J.M. and Avruch, J. 1996. Protein kinase cascades activated by stress and inflammatory cytokines. Bioessays 18: $567-577$.

Li, J., Yang, Y., Peng, Y., Austin, R.J., van Eyndhoven, W.G., Nguyen, K.C., Gabriele, T., McCurrach, M.E., Marks, J.R., Hoey, T., et al. 2002. Oncogenic properties of PPM1D located within a breast cancer amplification epicenter at 17q23. Nat. Genet. 31: 133-134.

Lopez-Girona, A., Tanaka, K., Chen, X.B., Baber, B.A., McGowan, C.H., and Russell, P. 2001. Serine-345 is required for Rad3-dependent phosphorylation and function of checkpoint kinase Chk1 in fission yeast. Proc. Natl. Acad. Sci. 
Lu et al.

98: 11289-11294.

Liu, Q., Guntuku, S., Cui, X.S., Matsuoka, S., Cortez, D., Tamai, K., Luo, G., Carattini-Rivera, S., DeMayo, F., Bradley, A., et al. 2000. Chk1 is an essential kinase that is regulated by Atr and required for the G(2)/M DNA damage checkpoint. Genes \& Dev. 14: 1448-1459.

Lu, X., Bocangel, D., Nannenga, B., Yamaguchi, H., Appella, E., and Donehower, L.A. 2004. The p53-Induced oncogenic phosphatase PPM1D interacts with uracil DNA glycosylase and suppresses base excision repair. Mol. Cell 15: 621-634.

Maya, R., Balass, M., Kim, S.T., Shkedy, D., Leal, J.F., Shifman, O., Moas, M., Buschmann, T., Ronai, Z., Shiloh, Y., et al. 2001. ATM-dependent phosphorylation of $M d m 2$ on serine 395: Role in p53 activation by DNA damage. Genes \& Dev. 15: 1067-1077.

Mumby, M.C. and Walter, G. 1993. Protein serine/threonine phosphatases: Structure, regulation, and functions in cell growth. Physiol. Rev. 73: 673-699.

Parker, L.L. and Piwnica-Worms, H. 1992. Inactivation of the p34cdc2-cyclin B complex by the human WEE1 tyrosine kinase. Science 257: 1955-1957.

Saito-Ohara, F., Imoto, I., Inoue, J., Hosoi, H., Nakagawara, A., Sugimoto, T., and Inazawa, J. 2003. PPM1D is a potential target for 17q gain in neuroblastoma. Cancer Res. 63: 18761883.

Sancar, A., Lindsey-Boltz, L.A., Unsal-Kaccmaz, K., and Linn, S. 2004. Molecular mechanisms of mammalian DNA repair and the DNA damage checkpoints. Annu. Rev. Biochem. 73: 39-85.

Sanchez, Y., Wong, C., Thoma, R.S., Richman, R., Wu, Z., Piwnica-Worms, H., and Elledge, S.J. 1997. Conservation of the Chk1 checkpoint pathway in mammals: Linkage of DNA damage to Cdk regulation through Cdc25. Science 277: 1497-1501.

Shieh, S.Y., Ikeda, M., Taya, Y., and Prives, C. 1997. DNA damage-induced phosphorylation of p53 alleviates inhibition by MDM2. Cell 91: 325-334.

Shiloh, Y. 2003. ATM and related protein kinases: Safeguarding genome integrity. Nat. Rev. Cancer 3: 155-168.

Sluss, H.K., Armata, H., Gallant, J., and Jones, S.N. 2004. Phosphorylation of serine 18 regulates distinct p53 functions in mice. Mol. Cell. Biol. 24: 976-984.

Takekawa, M., Maeda, T., and Saito, H. 1998. Protein phosphatase $2 \mathrm{C} \alpha$ inhibits the human stress-responsive p38 and JNK MAPK pathways. EMBO J. 17: 4744-4752.

Takekawa, M., Adachi, M., Nakahata, A., Nakayama, I., Itoh, F., Tsukuda, H., Taya, Y., and Imai, K. 2000. p53-inducible wip1 phosphatase mediates a negative feedback regulation of p38 MAPK-p53 signaling in response to UV radiation. EMBO J. 19: 6517-6526.

Tibbetts, R.S., Brumbaugh, K.M., Williams, J.M., Sarkaria, J.N., Cliby, W.A., Shieh, S.Y., Taya, Y., Prives, C., and Abraham, R.T. 1999. A role for ATR in the DNA damage-induced phosphorylation of p53. Genes \& Dev. 13: 152-157.

Vousden, K.H. and Lu, X. 2002. Live or let die: The cell's response to p53. Nat. Rev. Cancer 2: 594-604.

Xu, B., Kim, S.T., Lim, D.S., and Kastan, M.B. 2002. Two molecularly distinct $\mathrm{G}(2) / \mathrm{M}$ checkpoints are induced by ionizing irradiation. Mol. Cell. Biol. 22: 1049-1059.

Zhao, H. and Piwnica-Worms, H. 2001. ATR-mediated checkpoint pathways regulate phosphorylation and activation of human Chk1. Mol. Cell. Biol. 21: 4129-4139.

Zhou, B.B. and Elledge, S.J. 2000. The DNA damage response: Putting checkpoints in perspective. Nature 408: 433-439. - 2003. Sensing DNA damage through ATRIP recognition of RPA-ssDNA complexes. Science 300: 1542-1548 


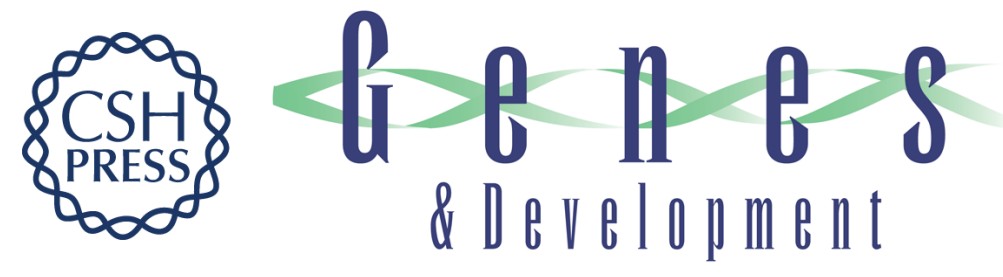

\section{PPM1D dephosphorylates Chk1 and p53 and abrogates cell cycle checkpoints}

Xiongbin Lu, Bonnie Nannenga and Lawrence A. Donehower

Genes Dev. 2005, 19:

Access the most recent version at doi:10.1101/gad.1291305

References This article cites 47 articles, 24 of which can be accessed free at: http://genesdev.cshlp.org/content/19/10/1162.full.html\#ref-list-1

License

Email Alerting

Receive free email alerts when new articles cite this article - sign up in the box at the top Service right corner of the article or click here.

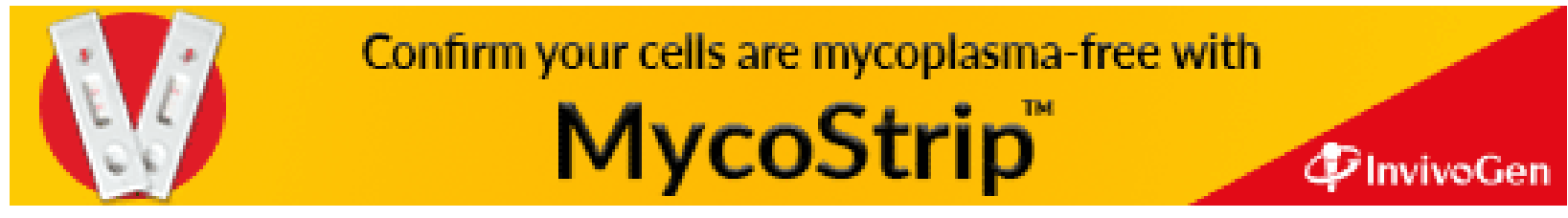

